\title{
A Orientação para o Mercado sob a Ótica da Empresa e dos Clientes na Indústria Hoteleira Gaúcha
}

\author{
Rogério Gava \\ Teniza da Silveira
}

\section{ResUMo}

\begin{abstract}
A despeito do notório desenvolvimento da pesquisa no âmbito da orientação para o mercado nos últimos quinze anos, verifica-se a visão unilateral que os estudos têm imputado ao tema, baseada somente na percepção dos executivos da própria organização. Raros são os trabalhos que contemplam a perspectiva do cliente, além daquela das empresas, comparando-as. O objetivo deste artigo foi o de investigar as diferenças entre as auto-avaliações das empresas e as avaliações dos respectivos clientes, relativas ao grau de Orientação Para o Mercado, em pesquisa realizada em dois pólos turísticos do Rio Grande do Sul. Como forma de mensuração da lacuna de orientação para o mercado, empregou-se a escala desenvolvida por Deshpandé, Farley e Webster (1993). Os resultados evidenciaram a existência da Lacuna de Orientação para o Mercado na indústria estudada. Além disso, observou-se relação do grau de orientação com o desempenho apenas na dimensão empresa, não sendo detectada associação positiva e direta entre as percepções dos clientes e o desempenho das organizações investigadas. Os resultados relativos ao desempenho reforçam a necessidade de mais estudos na área, que possam trazer subsídios ao aprimoramento da questão.
\end{abstract}

Palavras-chave: orientação para o mercado; lacuna de orientação para o mercado; performance empresarial; marketing na indústria hoteleira.

\begin{abstract}
Despite the notorious development of research in the market orientation field on the last fifteen years, there is a unilateral approach in these studies, based only in the perceptions of the organizations managers. Researches that deal with the perspective of the costumers - comparing with the company perception - are unusual. The aim of this article is to investigate the Market Orientation Gap in a research carried out with two tourism regions on the Rio Grande do Sul, Brazil. The scale developed by Deshpandé, Farley and Webster (1993) was employed here. The results show the existence of the market orientation gap in the industry analyzed. Moreover, the relation between market orientation and performance was observed, only at the company perspective, but no link was observed between customers' perception and the performance of the firms. Future research is needed to shade more light in this field of study.
\end{abstract}

Key words: market orientation; market orientation gap; company's performance; marketing in the hotel industry. 


\section{INTRODUÇÃO}

Uma análise histórica dos trabalhos realizados no âmbito da orientação para o mercado revela que a mensuração do construto - na quase totalidade dos trabalhos - dá-se unicamente a partir da auto-avaliação das organizações investigadas. A questão tem suscitado a realização de pesquisas que direcionem as avaliações para além da empresa. Dentro dessa perspectiva, alguns trabalhos têm evidenciado interesse em ampliar a abrangência das investigações na área, entendendo ser indispensável incluir em seu escopo dimensões como clientes, fornecedores, funcionários e demais públicos de interesse das organizações. Nessa concepção, surge o conceito da lacuna de orientação para o mercado (Steinman, Deshpandé, \& Farley, 2000), representada pelas diferenças entre as percepções que empresas e clientes mantêm sobre o grau de orientação assumido.

A questão apresentada relaciona-se com o aspecto do desempenho organizacional. Para alguns autores, esforços de orientação não percebidos pelos clientes podem diminuir os resultados oriundos da orientação para o mercado (Langerak, 2001; Webb, Webster, \& Krepapa, 2000). Esses autores entendem que uma estratégia de orientação para o mercado tem sua eficácia diminuída, se não for efetivamente percebida pelos clientes da organização. Tal constatação assinala a importância do conceito da lacuna de orientação para o mercado. A avaliação da orientação para mercado, a partir do ponto de vista dos clientes, pode revelar as inconsistências de opiniões que empresas e consumidores mantêm sobre o grau de orientação analisado, servindo de base para futuras avaliações e gerenciamentos. Tal aspecto pode servir também para verificar a propriedade dos investimentos num maior grau de orientação, tendo em vista o desempenho obtido. Assim, estudos na área têm sido direcionados a esse aspecto particular, buscando conhecer sua natureza e influência sobre as ações de orientação implementadas.

Neste artigo, investiga-se a percepção de orientação para mercado sob a ótica de clientes e de executivos da indústria hoteleira. Sua estrutura compreende a apresentação do problema de pesquisa, a proposição dos objetivos, o quadro teórico que subsidiou a construção das hipóteses, o método empregado, a discussão dos resultados e as considerações finais. 


\section{O Problema de Pesquisa}

No contexto do universo turístico, os estudos de marketing têm alcançado o âmbito da indústria hoteleira (Gray, Matear, \& Matheson, 2000; Harris \& Watkins, 1998; Sargeant \& Mohamad, 1999). Aqui, assume-se o papel fundamental e a influência que a hospedagem, enquanto formadora do produto turístico, exerce sobre a satisfação dos clientes. Nesse particular, denota-se que o nível de implementação das ações de marketing no setor não parece acompanhar a evolução observada em outros segmentos inseridos no contexto dos serviços (Appiah-Adu, Fyall, \& Singh, 2000; Gray et al., 2000).

As constatações precedentes revestem-se de importância no contexto turístico gaúcho, marcado por notável crescimento nos últimos dez anos. Essa expansão fomentou o crescimento do parque hoteleiro regional, promovendo investimentos de empreendedores locais e estrangeiros. Nessa perspectiva, cresce a necessidade de realização de investigações que explorem a questão do marketing no setor.

Nesse artigo, buscou-se contemplar a questão do marketing na indústria hoteleira a partir do paradigma de orientação para o mercado. Em particular, foi agregado ao tema o conceito da lacuna de orientação, avaliando também as percepções emitidas pelos clientes das empresas pesquisadas. Em face do disposto, o problema de pesquisa do presente trabalho relaciona-se com a seguinte questão:

Existem diferenças entre as auto-avaliações das empresas e as avaliações dos respectivos clientes, relativas ao grau de Orientação Para o Mercado na indústria hoteleira gaúcha?

\section{Овjetivos}

\section{Objetivo Geral}

Avaliar o grau de orientação para o mercado na indústria hoteleira gaúcha segundo a auto-avaliação das empresas e a avaliação dos clientes.

\section{Objetivos Especificos}

a) mensurar o desempenho organizacional das empresas pesquisadas através da aplicação dos seguintes indicadores: taxa de ocupação anual (quociente 
entre o número de Unidades Habitacionais (UHs) ocupadas e o número de UHs disponíveis para ocupação no ano; tarifa média anual (total da receita pelo número de UHs ocupadas no ano), e lucratividade (relação entre o Lucro Líquido e a Receita Líquida no período determinado);

b) avaliar as percepções dos hóspedes, relativas ao grau de orientação para o mercado da empresa analisada;

c) analisar a relação entre o desempenho organizacional e a orientação para o mercado na avaliação das empresas e na avaliação dos clientes;

d) comparar as auto-avaliações das empresas com as avaliações dos clientes, examinando divergências e/ou semelhanças entre as duas percepções, e a possível existência da lacuna de orientação para o mercado.

\section{Quadro Térico}

No contexto da orientação para o mercado, os estudos iniciais de Kohli e Jaworski (1990), Narver e Slater (1990), Deshpandé, Farley e Webster (1993), e Day (1994) ocupam lugar de destaque. O construto de Kohli e Jaworski situa a orientação para o mercado a partir das ações de geração de inteligência de mercado, sua disseminação por toda a empresa, e a subseqüente resposta à inteligência gerada. A inteligência de mercado envolve a análise dos diversos fatores que podem influenciar as necessidades dos consumidores; sua geração corresponde à busca de conhecimento sobre o mercado e sua influência sobre o comportamento dos clientes. Uma vez gerada, a inteligência deve ser disseminada por toda a organização, sendo transformada em ações concretas voltadas à real satisfação das necessidades e expectativas dos consumidores.

Narver e Slater (1990) apresentam a orientação para o mercado, formando-se a partir da união de três elementos comportamentais: orientação para o cliente, orientação para o concorrente, e coordenação interfuncional. Esses, em estreita consonância com decisões relativas à visão de longo prazo e lucratividade. Por orientação para o cliente entendem a capacidade em criar valor para os consumidores de forma constante e na disseminação destas informações por toda a organização. A orientação para o concorrente pressupõe o conhecimento de suas forças e fraquezas de curto prazo, bem como das competências e estratégias de longo prazo de concorrentes atuais e potenciais. Finalmente, cabe à coordenação interfuncional aglutinar todos os esforços da empresa - e não apenas do marketing - em prol da criação de um valor superior para os clientes-alvo. 
Deshpandé et al. (1993), se, em um primeiro momento, expõem a natureza da orientação para o mercado sob um prisma cultural, em trabalhos posteriores (Deshpandé \& Farley, 1998a, 1998b) redirecionam seu pensamento a respeito da questão da cultura, passando a adotar uma perspectiva mais operacional ao abordar o tema. Assim, definem a orientação para o mercado como um conjunto de atividades relacionadas à constante satisfação das necessidades dos clientes.

Na perspectiva de Day (1994), a orientação para o mercado representa a habilidade superior em entender e satisfazer os clientes, tarefa que se relaciona inequivocamente à questão das capacidades (capabilities). Uma organização orientada ao mercado possui as capacidades superiores de senso de mercado e ligação com o consumidor. Ter senso de mercado é ter a capacidade de sentir os eventos e tendências do ambiente de forma mais avançada que os competidores. A ligação com o consumidor define-se como a capacidade em criar e gerenciar relacionamentos com os clientes.

A teoria de orientação para o mercado contemplou, desde sua origem, apenas a perspectiva da empresa na mensuração do construto (Kohli, Jaworski, \& Kumar, 1993; Narver \& Slater, 1990). Assim, as pesquisas sempre se apresentaram sob uma metodologia que privilegiava eminentemente a auto-avaliação emitida pelos executivos das organizações. O trabalho de Deshpandé et al. (1993) foi o pioneiro a abordar a questão do cliente e sua percepção sobre o nível de orientação para o mercado. Nesse sentido, considerava o cliente - e seu ponto de vista - como um momento crítico das pesquisas sobre o tema.

O conceito de Lacuna de Orientação Para o Mercado surge com o trabalho de Steinman et al. (2000), assumindo a inconsistência de opiniões entre empresas e clientes sobre o grau de orientação para o mercado avaliado. Para os autores, conhecer a percepção dos clientes a respeito do grau de orientação para o mercado, é crucial para a empresa identificar quão orientada ela precisa ser. Em última análise, o nível apropriado de orientação é aquele que o cliente considera satisfatório.

A orientação para o mercado na perspectiva do cliente também é o foco do trabalho de Webb et al. (2000). Os autores destacam que a análise tomada unicamente a partir da empresa propicia uma definição míope e unilateral do construto, ignorando aspectos vitais em termos de geração de valor para os clientes. Nesse contexto, trazem à questão o conceito de orientação para o mercado definida pelo cliente (costumer-defined market orientation).

Em Langerak (2001), o processo de apenas uma via na pesquisa de orientação para o mercado também é visto como insuficiente. Aqui, afirma-se que os benefícios de longo prazo, advindos de uma postura de orientação, são verdadeiramente sentidos, 
quando há forte correlação entre as percepções da empresa e de seus públicos de interesse. $\mathrm{O}$ autor conclui que a diminuição da lacuna de orientação passa por uma mudança na maneira como as empresas se relacionam no mercado, ou seja, de um gerenciamento de transações, para um gerenciamento de relacionamentos.

Krepapa, Berthon, Webb e Pitt (2003) enfatizam a propriedade de os estudos organizacionais adotarem múltiplas perspectivas ao estudarem fenômenos como o de orientação para o mercado. Para eles, tal procedimento se alicerça na própria teoria de orientação, onde o foco no consumidor - um de seus componentes fundamentais - pressupõe o reconhecimento do grau de orientação por parte dos clientes da empresa.

O conceito de viés de desejabilidade social (social desirability bias) pode ser relacionado às considerações precedentes. Aqui, entende-se que as mensurações tomadas a partir de questionários auto-avaliativos podem ser desvirtuadas pelo desejo dos respondentes em evitar embaraços, ao mesmo tempo que buscam projetar uma imagem favorável a terceiros (Arnold \& Feldman, 1981; Fisher, 1993; Ganster, Hennessey, \& Luthans, 1983; Keillor, Owens, \& Pettijohn, 2001). As escalas de medição do grau de orientação para o mercado, ao utilizarem questionários de auto-avaliação para a coleta dos dados, podem dar margem a que os participantes, consciente ou inconscientemente, conformem suas respostas aos padrões e valores sociais e culturais em que se inserem. Nesse contexto, a introdução da análise junto aos clientes representa uma tentativa de amenizar os efeitos do viés de desejabilidade social da pesquisa sobre orientação para o mercado.

Em face das considerações até aqui expostas, estabelece-se a primeira hipótese do presente trabalho:

\section{$H_{1}$ - O grau de orientação para o mercado segundo a auto-avaliação das empresas hoteleiras é maior do que o observado na avaliação feita pelos clientes, indicando a existência da lacuna de orientação para o mercado.}

A questão do desempenho organizacional e sua relação com a orientação para o mercado têm sido o enfoque central de diversos estudos concernentes ao tema. Nesse contexto, os resultados geralmente apontam para uma relação positiva entre a postura de orientação para o mercado e o conseqüente desempenho superior das organizações (Chang \& Chen, 1998; Jaworski \& Kohli, 1993; Narver \& Slater, 1990; Pelham, 1997; Perin \& Sampaio, 2001; Slater \& Narver, 1994; Van Egeren \& O'Connor, 1998).

Nem sempre, porém, a relação descrita se apresenta de forma positiva. Inúmeras variáveis podem interferir positiva ou negativamente nos efeitos da orientação 
sobre o desempenho. Trabalhos pioneiros de Kohli e Jaworski (1990) e Narver e Slater (1990) citam os moderadores ambientais, contingências do ambiente sob as quais o impacto da orientação para o mercado sobre o desempenho é sensivelmente diminuído. Posteriormente, os efeitos inequívocos dos moderadores ambientais são revistos pelos próprios autores (Jaworski \& Kohli, 1993; Slater \& Narver, 1994), demonstrando que fatores contingenciais externos não podem ser tomados como influenciadores inquestionáveis na relação entre a orientação para o mercado e o desempenho da empresa.

Langerak (2002), realizando uma meta-análise retrospectiva a partir de quarenta trabalhos que relacionam a orientação para o mercado com o desempenho no período 1990/2002, demonstra a alta variabilidade dos resultados, em detrimento de fatores como os indicadores utilizados, escalas de mensuração, contexto em que a pesquisa é realizada, tipo de organização, moderadores ambientais, e o próprio método de investigação empregado.

Assim, a questão do desempenho apresenta-se complexa e ainda sob intenso debate. Dependendo do contexto em que é estudada, pode espelhar resultados distintos. Sob o paradigma da Lacuna de Orientação, tal fato reflete-se sob considerações particulares. Nesse sentido, entende-se que as avaliações das empresas - inflacionadas pelos efeitos do viés de desejabilidade social - apresentem menor relação com o desempenho das empresas do que aquele medido junto aos respectivos clientes das organizações.

As evidências relacionadas até aqui apóiam a formulação das seguintes hipóteses de pesquisa:

$\mathrm{H}_{2}$ - A relação da orientação para o mercado com a performance organizacional é mais significativa na auto-avaliação dos clientes do que na avaliação das empresas hoteleiras.

$\mathrm{H}_{3}$ - O grau de orientação para o mercado segundo a auto-avaliação das empresas hoteleiras relaciona-se positivamente com a performance organizacional.

$\mathrm{H}_{4}$ - O grau de orientação para o mercado segundo a avaliação dos clientes relaciona-se positivamente com a performance organizacional.

No universo específico da hotelaria, a medição do desempenho das organizações aponta para a utilização histórica de alguns indicadores em particular. Nesse contexto, a Taxa de Ocupação e a Tarifa Média constituem-se em referenciais para as empresas hoteleiras mensurarem sua performance. Analisados em conjunto com a Lucratividade, os indicadores descritos completam a análise do desempenho empresarial aqui delineado. 
A taxa de ocupação constitui-se em indicador de suma importância no âmbito da indústria hoteleira, estando estreitamente relacionado à análise do equilíbrio operacional das empresas. Em face da realidade em que se inserem, marcada por fatores como a sazonalidade, venda de pacotes fechados a operadoras, baixa temporada, acordos de descontos para empresas (tarifa corporativa), entre outros, as empresas hoteleiras vêem-se às voltas com políticas de preços que reduzem sobremaneira sua lucratividade. Nesse sentido, a análise da tarifa média e sua relação com a taxa de ocupação obtida denotam em que medida as reduções no preço estão promovendo incremento ou reduções no desempenho financeiro da empresa.

Completando o quadro, o conceito de lucratividade das vendas constitui indicador relevante no contexto da análise empresarial, apontando a eficiência da empresa em lucrar por meio de suas atividades. A análise conjunta dos indicadores citados em face da lucratividade revela importantes subsídios ao gerenciamento dos hotéis. Dados do setor demonstram que desempenhos superiores são atingidos, quando derivados de altos índices de ocupação, mas sem sacrifício da tarifa praticada (Medlik \& Ingram, 2002).

Assim, a mensuração do desempenho no âmbito do presente estudo utiliza os indicadores até aqui apresentados. Sobre esses, constroem-se as seguintes hipóteses de pesquisa, completando o quadro conceitual do trabalho.

$H_{3 A}$ - A taxa de ocupação das empresas do setor hoteleiro aumenta na ordem direta do grau de orientação para o mercado mensurado na autoavaliação.

$\mathrm{H}_{3 \mathrm{~B}}$ - A tarifa média das empresas do setor hoteleiro é tanto maior quanto maior for o grau de orientação para o mercado mensurado na auto-avaliação.

$H_{3 C}$ - A lucratividade relaciona-se positivamente com o grau de orientação para o mercado mensurado na auto-avaliação das empresas.

$H_{44}$ - A taxa de ocupação das empresas do setor hoteleiro aumenta na ordem direta do grau de orientação para o mercado mensurado na avaliação dos clientes.

$\mathrm{H}_{4 \mathrm{~B}}$ - A tarifa média das empresas do setor hoteleiro é tanto maior quanto maior for o grau de orientação para o mercado mensurado na avaliação dos clientes.

$\mathbf{H}_{4 \mathrm{C}}$ - A lucratividade relaciona-se positivamente com o grau de orientação para o mercado mensurado na avaliação dos clientes. 
A seguir, apresenta-se o método adotado na pesquisa.

\section{MÉtodo}

A pesquisa realizada abrangeu duas fases distintas: uma exploratória, onde se buscou avaliar em que medida os hóspedes conseguem perceber aspectos internos das empresas hoteleiras. A segunda fase, descritiva, abrangeu a aplicação da escala de Orientação Para o Cliente de Deshpandé et al. (1993) nas dimensões empresas e respectivos clientes.

\section{Pesquisa Exploratória}

O método exploratório utilizado contemplou uma pesquisa qualitativa efetuada pelo processo de entrevistas em profundidade. As questões consistiram em um roteiro não-estruturado aplicado de forma individual a um grupo de onze indivíduos com experiência enquanto hóspedes de hotéis. Além disso, uma variação na freqüência com que os entrevistados costumam hospedar-se em hotéis também foi observada. A dimensão qualitativa do trabalho também contemplou a realização de entrevistas com seis especialistas, atuantes e estudiosos no âmbito do turismo e da hotelaria. O objetivo das entrevistas realizadas foi observar a capacidade das pessoas em avaliar aspectos internos, quando hóspedes de hotéis.

Os dados oriundos da pesquisa exploratória foram analisados através da técnica de análise de conteúdo (Cooper \& Schindler, 2003; Malhotra, 2001). A comunicação global foi decomposta em unidades de análise, onde elementos como palavras, frases, associações, temas, constituíram-se em indicadores do conteúdo da mensagem em exame.

\section{Pesquisa Descritiva}

\section{PlanoAmostral}

A pesquisa descritiva abrangeu o universo de empresas hoteleiras de médio (com 41 UHs até 200 UHs) e grande porte (mais de 200 UHs), localizadas em duas rotas turísticas localizadas no Estado do Rio Grande do Sul. Trata-se da Rota Turística Uva e Vinho, integrando 21 municípios de colonização italiana, e a Rota Romântica, formada por 13 municípios de colonização alemã. Um total de 48 empresas enquadraram-se nos parâmetros citados, 21 localizadas em 7 cidades da Rota Uva e Vinho, e 27 situadas em 5 cidades da Rota Romântica. A 
construção da amostra seguiu o modelo não-probabilístico, técnica amostral nãoaleatória de reconhecida utilização prática (Cooper \& Schindler, 2003; Malhotra, 2001; McDaniel \& Gates, 2003).

\section{Coleta dos Dados}

Devido às características da investigação - envolvimento de dois respondentes por empresa, e principalmente pela necessidade de acesso aos clientes - foram visitados pessoalmente todos os 48 hotéis listados a partir da pesquisa exploratória. Foi disponibilizado ao responsável pela direção e/ou gerência, o material relativo à coleta dos dados, constando de duas cópias do questionário com a escala de medição, e um questionário para a caracterização da empresa. Também, solicitouse a indicação de dez hóspedes com os devidos dados para contato posterior. As empresas foram visitadas no período de 01.12.2003 a 31.01.2004. Considerando que a taxa de retorno das empresas e clientes ficou aquém do esperado, foi efetuado um follow-up, em que se colocou como prazo limite a data de 10.03.2004 para o recebimento final das respostas. Findo o prazo de coleta, obteve-se um total de vinte retornos. Desses, oito foram excluídos, por não terem sido respondidos de forma satisfatória. Em relação aos hóspedes das 12 empresas restantes, obtevese um retorno de 50 questionários.

\section{Instrumento de Coleta}

A dimensão descritiva contemplou a utilização da escala proposta por Deshpandé et al. (1993) e aplicada também em Steinman et al. (2000). Esse instrumento reproduz as questões originais aplicadas na dimensão empresa, contemplando as adaptações semânticas e estruturais necessárias para torná-las passíveis de aplicação na dimensão clientes. Salienta-se também que a coleta de dados primários envolveu a obtenção de informações de cunho organizacional, contábil e financeiro (dados de caracterização) relativas às empresas participantes.

Os 9 itens componentes da escala foram apresentados aos respondentes na forma de afirmativas, sobre os quais eles manifestaram sua concordância ou não, através da escala Likert de 5 (cinco) pontos, variando de discordo totalmente a concordo totalmente. Nas empresas, os questionários foram respondidos por profissionais ligados à alta administração (proprietários, diretores, e gerentes gerais). Quanto aos clientes, foram selecionados aqueles com histórico de relacionamento com o hotel. O arcabouço amostral para tal seleção constituiu-se em listagem disponibilizada pela empresa, constando o nome e contato de dez hóspedes com o perfil designado. 


\section{Tratamento dos Dados}

A análise e interpretação dos dados obtidos na fase descritiva foi feita com o auxílio do software estatístico SPSS 11.0, com a utilização das seguintes ferramentas estatísticas: a) análise do viés de não-respondentes, com o intuito de verificar-se a propriedade de extrapolação dos dados, através das técnicas de comparação e extrapolação; b) análise multivariada (análise de componentes principais) para a identificação dos outliers, com o objetivo de identificar padrões de comportamento e valores que não correspondem ao padrão coletivo dos nove itens avaliados na pesquisa; c) testes de confiabilidade (Coeficiente Alpha de Cronbach) e validade (Análise Fatorial); d) teste $t$ de Student, para verificar a existência da lacuna de orientação; e) testes de correlação pelo Coeficiente de Pearson, permitindo verificar os níveis em que as hipóteses assumidas se confirmaram, ou não, na prática.

\section{Resultados da Pesquisa}

No âmbito da pesquisa exploratória, destaca-se que as questões atinentes à percepção dos hóspedes sobre aspectos internos do hotel denotaram a dificuldade daqueles em avaliar tal dimensão. Os entrevistados admitiram que prestam pouca atenção na dinâmica de funcionários e gerências. Apenas a partir de setores como a recepção podem transpirar alguns aspectos organizacionais, traduzidos em falta de comunicação e mau atendimento.

$\mathrm{Na}$ análise descritiva, ressalta-se inicialmente a possibilidade de extrapolação dos dados. Constatou-se a similaridade dos resultados entre os grupos de respondentes e não-respondentes, bem como entre as empresas que responderam à pesquisa de imediato e aquelas que só o fizeram a partir de um segundo contato. Considerando a semelhança entre as respostas pós-notificação e as dos nãorespondentes, pode-se considerar os dados obtidos na amostra para o total do universo pesquisado. Salienta-se, porém, que mesmo sob a permissão da análise há que se considerar o pequeno número de respondentes da amostra, fator limitante e que sinaliza os cuidados que importa tomar em termos de extrapolações. Ainda, destaca-se que a manutenção da taxa final de respondentes ( 24 executivos e 50 clientes) foi autorizada pela análise dos outliers, não tendo sido observados resultados discrepantes da média geral do grupo e que, caso existentes, teriam de ser descartados.

A confiabilidade da escala utilizada, ou seja, sua capacidade de produzir resultados consistentes a partir de repetidas medições, foi comprovada pela aplicação do 
coeficiente Alpha de Cronbach. Os resultados (0,9288 na dimensão cliente, e 0,8567 na dimensão empresa) apresentaram-se como satisfatórios em face dos parâmetros evidenciados pela literatura.

A validade do instrumento, revelando sua aptidão em medir realmente aquilo a que se propõe, foi verificada pela análise fatorial. Apesar do pequeno tamanho da amostra, a propriedade de uso dessa análise foi determinada por testes prévios específicos (Kaiser-Meyer-Olkin [KMO] e esfericidade de Bartlett). Os resultados evidenciaram que as variações observadas nos dados se relacionaram a fatores explicativos robustos. No âmbito das empresas, três fatores (ou componentes) foram responsáveis por quase $50 \%$ da variabilidade, enquanto na dimensão cliente apenas um fator respondeu por $64,5 \%$ da variação. Assim, observou-se que as diferentes variáveis utilizadas na medição referiram-se ao mesmo conceito, assegurando a validade da escala empregada.

\section{Caracterização da Amostra}

Com base no retorno obtido (12 empresas), pode-se destacar a participação de 11 empresas $(91,67 \%$ ) classificadas como médias (com 40 a 200 UHs) e apenas 1 empresa grande (8,33\%), com oferta de mais de 200 Unidades Habitacionais. Ressalta-se que os hotéis componentes da amostra enquadraram-se nas categorias Superior $(41,7 \%)$ e Turístico $(58,3 \%)$. O tempo médio de atividade ficou na casa dos 20 anos, sendo o número médio de colaboradores por empresa equivalente a 36 funcionários.

Em relação aos indicadores de desempenho, as empresas apresentaram uma taxa de ocupação média de 53,5\%, ligeiramente superior à média nacional de 50\% (Embratur, 2004). Observa-se porém, que 4 empresas (1/3 da amostra) exibiram médias inferiores. A análise das tarifas médias praticadas, por sua vez, apresenta a maioria dos hotéis da amostra em níveis inferiores aos nacionais (75\%). Finalmente, o índice de lucratividade médio do grupo foi de 22,32\%.

\section{Análise da Lacuna de Orientação Para o Mercado}

Esta etapa envolveu a mensuração do grau de orientação para o mercado nas empresas participantes e clientes por elas indicados. A existência da lacuna de orientação para o mercado foi verificada através do teste $t$ de Student, relativo às médias de duas amostras independentes para cada hotel. $\mathrm{O}$ grau final de orientação para o mercado, nas duas dimensões, é apresentado na Tabela 1. Salienta-se que foram consideradas significativas diferenças no nível de significância de 5\%. 
Tabela 1: Níveis de Orientação para o Mercado na Avaliação das Empresas, Clientes, e a Respectiva Lacuna de Orientação

\begin{tabular}{l|c|c|c|c}
\hline Hotel & $\begin{array}{c}\text { Orientação para o } \\
\text { Mercado } \\
\text { Avaliação Empresa }\end{array}$ & $\begin{array}{c}\text { Orientação para o } \\
\text { Mercado } \\
\text { Avaliação Hóspedes }\end{array}$ & $\begin{array}{c}\text { Valor do } \\
\text { Teste }\end{array}$ & $\mathrm{p}$ \\
\hline 1 & 4,056 & 4,467 & 1,619 & 0,166 \\
\hline 2 & 4,222 & 3,889 & $-1,235$ & 0,271 \\
\hline 3 & 4,444 & 4,644 & 1,007 & 0,360 \\
\hline 4 & 4,222 & 3,244 & $-2,418$ & 0,073 \\
\hline 5 & 4,500 & 4,267 & $-1,107$ & 0,319 \\
\hline 6 & 2,611 & 2,622 & 0,021 & 0,984 \\
\hline 7 & 4,333 & 3,289 & $-11,017$ & 0,000 \\
\hline 9 & 4,667 & 3,833 & $-2,379$ & 0,076 \\
\hline 10 & 4,389 & 2,278 & $-7,165$ & 0,002 \\
\hline 11 & 3,556 & 4,222 & 4,025 & 0,028 \\
\hline 12 & 3,667 & 2,444 & $-7,778$ & 0,016 \\
\hline
\end{tabular}

Fonte: coleta de dados.

$\mathrm{n}_{\text {hotéis }}=24 ; \mathrm{n}_{\text {hóspedes }}=50$

Observa-se que a média geral do grau de orientação para o mercado foi de 4,060 nas empresas, e de 3,587 segundo a avaliação dos clientes. A diferença é significativa, com $\mathrm{t}=-2,749$ para $\mathrm{p}=0,008$, indicando a existência da lacuna de orientação. Essa foi confirmada também pelo teste t para amostras emparelhadas, o qual ratificou a significância do hiato entre as avaliações.

Os resultados descritos evidenciam a existência da lacuna de orientação para o mercado, dando sustentação à hipótese de pesquisa $\mathrm{H}_{1}$. Ressalte-se, contudo, que tal confirmação dá-se no conjunto, e não de forma individual. Assim, pode-se afirmar que os hotéis pesquisados, no geral, percebem-se mais orientados ao mercado do que seus clientes. Tal fato denota que os posicionamentos de orientação estão sendo percebidos pelos clientes em menor intensidade do que pelas empresas em estudo.

\section{Relação do Grau de Orientação Para o Mercado com a Performance}

Para avaliar a relação existente entre a orientação para o mercado e a performance das organizações, foi inicialmente mensurado o desempenho global das empresas, a partir da sua classificação em ordem decrescente, em face do escore final de performance obtido. Os escores individuais foram coletados em unidades de porcentagem (taxa de ocupação e lucratividade), e em valores monetários (tarifa média). 
Como os indicadores foram coletados em unidades distintas (taxa de ocupação e lucratividade em porcentagem; tarifa média em Reais), e, com o intuito de possibilitar comparações, procedeu-se à padronização dos valores. Tal técnica estatística é referendada pela literatura (Malhotra, 2001), sendo método corrente em publicações especializadas no gênero, como é o caso da Revista Exame Melhores e Maiores. Salienta-se que o escore final das empresas foi estabelecido através de uma ponderação que contemplou $25 \%$ de taxa de ocupação, $25 \%$ de tarifa média e $50 \%$ de lucratividade. Optou-se por atribuir maior peso à lucratividade, por ser o único indicador de desempenho econômico-financeiro coletado. Considerando que os outros dois indicadores (taxa de ocupação e tarifa média) relacionam-se ao desempenho em sua dimensão operacional, têm-se uma divisão equilibrada entre as medições nessas duas importantes áreas de gestão.

A partir do método proposto, obteve-se o seguinte quadro de valores padronizados e escore das empresas:

Tabela 2: Valores Padronizados e Escore Final

\begin{tabular}{llcccc}
\hline Hotel & Categoria & $\begin{array}{c}\text { Taxa } \\
\text { de Ocupação }(\mathrm{z})\end{array}$ & $\begin{array}{c}\text { Tarifa Média } \\
\text { Empresa/ } \\
\text { Indústria }(\mathrm{z})\end{array}$ & $\begin{array}{c}\text { Lucratividade } \\
(\mathrm{z})\end{array}$ & $\begin{array}{c}\text { Escore da } \\
\text { empresa }\end{array}$ \\
\hline 1 & Superior & 1,0548 & $-1,0678$ & 0,3008 & 0,1472 \\
2 & Turístico & $-0,0776$ & $-0,7275$ & 0,3293 & $-0,0366$ \\
3 & Superior & $-0,7032$ & $-0,3001$ & 0,6767 & 0,0875 \\
4 & Superior & 0,6847 & $-0,6839$ & 1,0527 & 0,5265 \\
5 & Superior & 0,3146 & 1,3399 & $-0,6391$ & 0,0941 \\
6 & Turístico & $-1,3001$ & $-0,8041$ & $-0,5909$ & $-0,8215$ \\
7 & Turístico & 1,8919 & $-0,9956$ & $-1,1201$ & $-0,3360$ \\
8 & Turístico & 0,0582 & 1,8763 & 0,1453 & 0,5563 \\
9 & Turístico & 0,0582 & 0,5361 & 0,6974 & 0,4973 \\
10 & Superior & $-1,3509$ & 0,7118 & $-1,3910$ & $-0,8553$ \\
11 & Turístico & 0,1940 & $-0,0383$ & $-1,0787$ & $-0,5004$ \\
12 & Turístico & $-0,8247$ & 0,1532 & 1,6177 & 0,6410 \\
\hline
\end{tabular}

Fonte: coleta de dados

$\mathrm{n}=12$

Para verificar-se a relação entre o grau de orientação para o mercado e o escore de desempenho organizacional, foi utilizada a análise de correlação. Tal método foi aplicado em relação às avaliações que empresas e clientes emitiram sobre o grau de orientação para o mercado das organizações, e sua relação com os resultados de desempenho coletados. A intensidade de associação entre as variáveis foi testada através do Coeficiente de Pearson.

Primeiramente, observou-se uma correlação positiva e significante em relação às avaliações das empresas (Coeficiente de Correlação de Pearson de 0,733 com $\mathrm{p}=$ 0,007), o que serve de sustentação para confirmar a hipótese $\mathrm{H}_{3}$. Válido salientar, contudo, que o desempenho - pela sua característica multidimensional - impõe sempre 
restrições às inferências a ele atinentes. Nesse sentido, pode-se afirmar que a relação foi verificada em condições específicas; a partir de outros indicadores e/ou sob condições temporais e contingenciais diversas, talvez se apresentasse de forma diferente. Como exemplo, cita-se o estudo desenvolvido por Sargeant e Mohamad (1999) junto a 200 hotéis de grande porte na Inglaterra, o qual não confirmou relação entre o grau de orientação das empresas e o desempenho, medido em termos de lucratividade e o volume total de vendas (turnover).

Passando à análise na esfera dos clientes, observa-se que a correlação não se repetiu. O Coeficiente de Correlação de Pearson foi de $-0,025 \operatorname{com} \mathrm{p}=0,938$, o que não confirmou a hipótese sustentada $\mathrm{H}_{4}$. Assim, não foi observada correlação positiva e significante entre o grau de orientação para o mercado medido na dimensão cliente e o desempenho das organizações estudadas.

Embora aplicado sob condições diferentes, é oportuno citar aqui o estudo desenvolvido por Au e Tse (1995) junto à indústria hoteleira em Hong Kong e na Nova Zelândia, o qual não evidenciou relação entre a orientação para o mercado e o desempenho medido pela taxa de ocupação. Destaca-se que esse trabalho utilizou um questionário adaptado às empresas participantes, para minimizar os efeitos do viés de desejabilidade social. Dessa forma, pode-se traçar um paralelo com a aplicação, na presente pesquisa, da escala adaptada aplicada na dimensão cliente, que também não apresentou relação em face do indicador descrito.

Por fim, a análise de correlação permitiu visualizar também a inexistência de relação entre as avaliações de empresas e clientes $(r=0,357 \mathrm{com} p=0,255)$. Assim, pode-se afirmar a diferença entre as avaliações, mas não um padrão de comportamento entre as respostas obtidas nas duas dimensões. Os níveis de orientação não apresentam relação, seja ela direta ou inversamente proporcional. Como comparativo, cita-se o estudo desenvolvido por Deshpandé et al. (1993), em que também não foi observada essa relação.

Algumas possibilidades podem ser levantadas a esse respeito. Primeiro, uma superestimação por parte das empresas dos graus de orientação ao mercado assumidos; também é possível que os clientes não consigam avaliar aspectos endógenos - culturais e estratégicos - relativos ao construto mensurado, acabando por posicionarem-se de forma neutra. Há de se considerar, ainda, o caráter de longo prazo dos efeitos de orientação, o que torna factível inferir que os esforços desenvolvidos pelas empresas ainda não tenham sido percebidos pelos clientes.

Tendo em vista que a relação entre as duas avaliações (empresas e clientes) com o desempenho organizacional denotou correlação somente entre as avaliações emitidas pelas empresas hoteleiras, fica afastada a sustentação da hipótese $\mathrm{H}_{2}$, que preconiza uma relação mais significativa da performance com a orientação percebida pelos clientes. 


\section{Relação do Grau de Orientação em Face dos Indicadores de Desempenho Utilizados}

Na dimensão empresa, ressalta-se o singular resultado obtido, em que a relação com o desempenho aparece quando tomada a partir dos três indicadores, no mesmo tempo em que em nenhum deles se manifesta de forma particular. Analisando possíveis determinantes para tal fato, é cabível propor que a soma das variáveis acabou por potenciar positivamente o resultado geral. Assim, resultados negativos e positivos - que, em relação a cada indicador, não forneceram correlação - quando tomados em conjunto equilibraram-se de forma casual, gerando a associação observada. Tal aspecto é sustentado pela teoria estatística (Cooper \& Schindler, 2003), asseverando que, muitas vezes, dados agregados geram correlação positiva, o que não ocorre quando tomados separadamente; em outros casos, a correlação só aparece na análise individual, não existindo quando tomada pelo conjunto de variáveis.

Portanto, não houve sustentação para as sub-hipóteses: $\mathrm{H}_{3 \mathrm{~A}}$, que propunha uma relação positiva e significante entre os índices de ocupação e o grau de orientação mensurado pelas organizações; $\mathrm{H}_{3 \mathrm{~B}}$, refutando a afirmação de que o indicador tarifa média tenha relação direta e significante com o grau de orientação verificado; e $\mathrm{H}_{3 \mathrm{C}}$, refutando o relacionamento positivo entre a orientação para o mercado com a lucratividade da empresa.

Na dimensão clientes, não foi observada associação nem de forma agregada, nem em relação a cada indicador em particular. Ficam refutadas, assim, as subhipóteses $\mathrm{H}_{4 \mathrm{~A}}$, mostrando que não há relação entre a percepção dos clientes com uma melhor ocupação dos hotéis; $\mathrm{H}_{4 \mathrm{~B}}$, não revelando relação entre médias mais satisfatórias relativas aos preços de balcão, praticados pelo hotel com a orientação para o mercado, percebida pelos clientes e $\mathrm{H}_{4 \mathrm{C}}$, não relacionando positivamente a orientação para o mercado medida junto aos clientes com a lucratividade da empresa.

A inexistência de correlação contraria a noção, expressa na literatura, de que as avaliações dos clientes se associam com mais intensidade ao desempenho das empresas. Entende-se que as opiniões dos clientes - os quais não têm compromisso com os resultados organizacionais - não são suscetíveis ao viés de desejabilidade social e, por isso, tendem a retratar a realidade de forma mais consistente.

O coeficiente observado demonstra que não houve um padrão de proporcionalidade, seja direto ou inverso, entre o grau de orientação medido e o desempenho empresarial. Assim, empresas com elevada orientação denotaram índices de lucratividade baixos, médios e altos; no mesmo tempo, empresas com baixa orientação apresentaram lucratividade variando de baixa a alta. A extrema 
difusão das avaliações dos clientes não possibilita descrever uma relação entre as variáveis de desempenho e o construto analisado.

\section{Considerações Finais}

Relativamente ao problema central da pesquisa, os resultados apontaram a existência da lacuna de orientação para o mercado na indústria pesquisada. Tais resultados evidenciam que as empresas, no conjunto, se posicionam com graus de orientação maiores do que aqueles percebidos pelos seus clientes (hipótese H1).

Em relação ao elo entre orientação para o mercado e desempenho, exibiu-se uma correlação somente na dimensão empresa, não sendo evidenciada relação entre o desempenho dos hotéis pesquisados com as avaliações dos seus respectivos clientes.

Ainda no campo do desempenho, não foi constatada relação da orientação para o mercado com nenhum dos indicadores utilizados para a construção dos escores de desempenho. Tanto na dimensão empresa, como na dimensão cliente, os escores representativos das taxas de ocupação, tarifa média e lucratividade não exibiram correlação significativa com o grau de orientação para o mercado assumido.

\section{Implicações Para a Administração}

A confirmação da lacuna de orientação para o mercado na indústria hoteleira demonstra que os esforços realizados pelas organizações não estão sendo percebidos pelos clientes sob a mesma intensidade. Tais fatos apontam para uma estimação mais intensa, por parte das empresas, dos posicionamentos de orientação assumidos. Isso é temerário para as organizações e para o setor como um todo, por entender-se orientada ao mercado em níveis superiores àqueles percebidos pelos clientes.

A identificação de diferenças entre o que a maioria das empresas pensa sobre si mesmas e o que seus clientes acreditam pede um direcionamento de esforços para que tal hiato seja suplantado. Nesse contexto, o marketing de relacionamento tem sido visto como fator antecedente ao fenômeno da lacuna de orientação (Steinman et al., 2000), evidenciando uma relação inversa entre a robustez do relacionamento com os clientes e o tamanho da lacuna observada. Tal fato sustenta a hipótese de que um histórico de relacionamento com os clientes está associado à baixa inconsistência de opiniões em relação ao grau de orientação para o mercado. Cumpre ressaltar que, no setor hoteleiro, dada a sua natureza, a prática de marketing de relacionamento encontra terreno fértil. Ainda assim, deve-se 
atentar para a predisposição ao relacionamento manifestada por diferentes segmentos de clientes atendidos por um hotel.

\section{Limitações da Pesquisa}

Uma análise crítica desta pesquisa possibilitou a identificação de limitações, que são descritas a seguir.

a) A inexistência de trabalhos que abordem a lacuna de orientação, levando em conta as avaliações de clientes finais (os trabalhos existentes em sua totalidade referem-se a relações empresa/empresa), impossibilita comparações mais concretas.

b) A identificação dos clientes, a partir de listagem fornecida pelas empresas, pode ter acarretado a inserção somente daqueles com histórico satisfatório junto às organizações e, assim, com maior probabilidade de emitirem opiniões favoráveis.

c) A dificuldade de coleta de dados junto aos clientes das organizações, e a consequiente opção por trabalhar-se com números diferentes de retornos em cada empresa, é fator que não pode ser desprezado nas análises pertinentes.

d) As considerações a respeito do desempenho empresarial limitam-se aos indicadores utilizados. Ainda, o estudo não se preocupou com possíveis moderadores ambientais e práticas estratégicas, que possam vir a afetar a relação entre o grau de orientação para o mercado e o desempenho observado.

e) O baixo índice de participação das empresas - em grande parte pela preocupação em permitir o acesso aos hóspedes - diminuiu consideravelmente a amplitude do trabalho.

\section{Sugestões para Estudos Futuros}

A replicação da presente pesquisa em momento futuro permitirá a visualização do comportamento da indústria hoteleira gaúcha em relação à orientação para o mercado assumida, bem como a avaliação que os clientes fazem a esse mesmo aspecto, em uma perspectiva temporal. Salienta-se que novas investigações também podem ser realizadas junto ao parque hoteleiro de outras regiões do estado e do país.

Pela inexistência de estudos nacionais que tratem o tema sob o prisma da lacuna de orientação, assume-se a importância de que pesquisas semelhantes venham a ser realizadas em outros setores da economia. 
A utilização de diferentes indicadores que não aqueles aqui implementados é também um tópico a ser observado em futuras investigações. A inexistência de relação entre os indicadores utilizados e os níveis de desempenho - o que ocorreu nas duas dimensões -, sugere que pesquisas subseqüentes utilizem outros meios de mensurar os escores de desempenho empresarial no meio hoteleiro.

Futuras investigações podem ser realizadas também para abordar o processo de orientação para o mercado e seus efeitos ao longo de toda a cadeia de valor da empresa. Nesse contexto, a lacuna de orientação para o mercado pode ser analisada não só em relação aos clientes, mas também em relação aos fornecedores, bem como focalizando outros públicos interessados na organização.

\section{Artigo recebido em 17.09.2004. Aprovado em 20.12.2004.}

\section{Referencias Bibliográficas}

Appiah-Adu, K.,

Fyall, A., \&

Singh, S. (2000, April).

Marketing culture and customer retention in the tourism industry. The Service Industries Journal, 20(2), 95113.

Arnold, H. J., \&

Feldman, D.C. (1981).

Social desirability response bias in self-report choice situations. Academy of Management Journal, 24(2), 377385.

Au, A. K. M., \&

Tse, A. C. B. (1995).

The effect of marketing orientation on company performance in the service sector: a comparative study of the hotel industry in Hong Kong and New Zealand. Journal of International Consumer Marketing, 8(2), 77-83.

Chang, T. Z., \&

Chen, S. J. (1998).

Market orientation, service quality and business profitability: a conceptual model and empirical evidence. The Journal of Services Marketing, 12(4), 246-261.

Cooper, R. D., \&

Schindler, P. S. (2003).

Métodos de pesquisa em Administração (7th ed). Porto Alegre: Bookman.

Day, G. S. (1994, October).

The capabilities of market-driven organizations. Journal of Marketing, $58,37-52$.

Deshpandé, R.,

Farley, J. U., \&

Webster, F. (1993, January).

Corporate culture, customer orientation, and innovativeness in japanese firms: a quadrad analysis. Journal of Marketing, 57(1), 23-37. 
Deshpandé, R., \&

Farley, J. U. (1998a).

Measuring market orientation: generalization and synthesis. Journal of Market Focused Management, 2(3), 213-232.

Deshpandé, R., \&

Farley, J. U. (1998b).

The market orientation construct: correlations, culture, and comprehensiveness. Journal of Market Focused Management, 2(3), 237-239.

Empresa Brasileira de Turismo EMBRATUR (2004).

Instituto Brasileiro de Turismo. Recuperado em 14 março, 2004, de http://www.embratur.gov.br

Fisher, R. J. (1993, September). Social desirability bias and the validity of indirecting questioning. Journal of Consumer Research, 20, 303-315.

Ganster, D. C.,

Hennessey, H. W., \&

Luthans, F. (1983).

Social desirability response effects: three alternative models. Academy of Management Journal, 26(2), 321-331.

Gray, B. J.,

Matear, S. M., \&

Matheson, P. K. (2000).

Improving the performance of hospitality firms. International Journal of Contemporary Hospitality Management, 12(3), 149-155.

Harris, L. C., \&

Watkins, P. (1998).

The impediments to developing a market orientation: an exploratory study of small UK hotels.

International Journal of

Contemporary Hospitality

Management, 10(6), 221-226.

Jaworski, B. J., \&

Kohli, A. K. (1993, July).

Market orientation: antecedents and consequences. Journal of Marketing, 57, 53-71.

Keillor, B.,

Owens, D., \&

Pettijohn, C. (2001, Winter).

A cross-cultural/croos-national study of influencing factors and socially desirable response biases. International Journal of Market Research, 43(1), 63-84.

Kohli, A. K., \&

Jaworski, B. J. (1990, April)

Market orientation: the construct, research propositions, and managerial implications. Journal of Marketing, 54, 1-18.

Kohli, A. K.,

Jaworski, B. J., \&

Kumar, A. (1993, November).

Markor: a measure of market orientation. Journal of Marketing Research, 30, 467-477.

Krepapa, A.,

Berthon, P.,

Webb, D., \&

Pitt, L. (2003).

Mind the gap: An analysis of service provider versus customer perceptions of market orientation and the impact on satisfaction. European Journal of Marketing, 37(1-2), 197-218. 
Langerak, F. (2001, First Quarter).

The relationship between customer and supplier perceptions of the manufacturer's market orientation and its business performance. International Journal of Market Research, 43(1), 43-62.

Langerak, F. (2002, October).

What is the predictive power of market orientation? Research in Management, ERIM Report Series reference number: ERS-2002-88-MKT.

McDaniel, C., \&

Gates, R. (2003).

Pesquisa de Marketing. São Paulo: Pioneira Thomson Learning.

Malhotra, N. K. (2001). Pesquisa de Marketing: uma orientação aplicada. (3rd ed.). Porto Alegre: Bookman.

Medlik, S., \&

Ingram, H. (2002).

Introdução à Hotelaria: gerenciamento e serviços. Rio de Janeiro: Campus.

Narver, J. C., \&

Slater, S. F. (1990, October).

The effect of a market orientation on business profitability. Journal of Marketing, 54, 20-35.

Pelham, A. M. (1997).

Mediating influences on the relationship between market orientation and profitability in small industrial firms. Journal of Marketing Theory and Pratice, 5(3), 55-76.
Perin, M. G., \&

Sampaio, C. H. (2001).

A relação entre as dimensões de orientação para mercado e a performance. Anais do Encontro Nacional dos Programas de PósGraduação em Administração, Campinas, SP, Brasil, 25.

Sargeant, A., \&

Mohamad, M. (1999, June).

Business performance in the U.K. hotel sector: does it pay to be market oriented? The Service Industries Journal, 19(3), 42-59.

Slater, S. F., \&

Narver, J. C. (1994, January).

Does competitive environment moderate the market orientationperformance relationship? Journal of Marketing, 58, 46-55.

Steinman, C.,

Deshpandé, R., \&

Farley, J. U. (2000).

Beyond market orientation: when customer and suppliers disagree. Journal of the Academy of Marketing Science, 28(1), 109-119.

Van Egeren, M., \&

O'Connor, S. (1998).

Drivers of market orientation and performance in service firms. The Journal of Services Marketing, 12(1), $39-58$.

Webb, D.,

Webster, C., \&

Krepapa, A. (2000, May).

An exploration of the meaning and outcomes of a costumer-defined market orientation. Journal of Business Research, 48(2), 101-112. 